\title{
Estimation of horizontal cover
}

\author{
WILLIAM B. COLLINS AND EARL F. BECKER
}

Authors are wildlife biologist, Alaska Department of Fish and Game, 1800 Glenn Hwy., Palmer, Alaska 99645; and biometrician, Alaska Department of Fish and Game, 333 Raspberry Rd., Anchorage, Alaska 99518.

\begin{abstract}
A method was developed to provide ecologists with an objective and efficient means for point sampling horizontal cover. This method produced estimates significantly $(p<0.05)$ more precise than cover pole and checkerboard methods, reducing variability among observers. The new method was significantly $(p<0.05)$ faster, than the other techniques. Factors affecting variability of measurements were reviewed.
\end{abstract}

Key Words: point sample, vegetation measurement, wildlife habitat

Three-dimensional distribution of vegetation significantly affects functional characteristics of plant communities such as snow accumulation, thermal transfers between animal and environment, predator/prey visibility, and the productivity and quality of understory forages. Ecologically, one of the most useful measurements of plant distribution is "cover", defined as the proportion of the ground surface occupied by a vertical projection of a plant's aerial parts (Greig-Smith 1964). Distribution of plants as viewed from a horizontal perspective is also significant, particularly as it relates to wildlife habitat values. Wildlife biologists frequently refer to the combined effects of horizontal and vertical cover in terms such as "thermal", "hiding", "screening", "escape", or "security" cover to indicate function.

The combined effects of vertical and horizontal cover may be determined through measurements of integrative variables such as wind speed, snow accumulation, light penetration, and radiant energy flux. However, actual cover in the horizontal perspective has been difficult to describe, because methods tended to be inefficient or subject to considerable observer bias. Methods available for determination of vertical cover are generally more objective and efficient than those available for estimation of horizontal cover (Bonham 1989, Higgins et al. 1994).

A personal computer program has proven useful for general assessment of hiding cover in forested stands where plant dimensional and density data are already available (Lyon and Marcum 1986). In settings where these data have not been obtained, or where integration of vegetation descriptors to estimate horizontal cover requires questionable assumptions, a more direct method is necessary.

Cover methods relying on point estimates have been considered more objective and less variable among observers than other

This project was funded by Federal Aid Wildlife Restoration Projects W-24-3 and W-24-4. Authors thank N. Cassara, A. Collins, L. Erie, H. Griese, M. Masteller, J. Miner, T. Miner, R. Modafferi, and S. Schmidt for their assistance.

Manuscript accepted 2 Apr. 2000.

\section{Resúmen}

Un método fué desarrollado para ofrecer ecólogos con un nudio objetivo y eficiente de se-alar cobertura horizontal. Este Método produjo un cálculo aproximado más preciso $(p<0.05)$ que polos cubiertos y métodos de tablero; reduciendo variabilidad entre los observadores. El método nuevo rápido $(p<0.05)$ que otras técnica. Los agentes que afectan la variabilidad de las mdeidas fueros revisados.

methods (Levy and Madden 1933, Bonham 1989). Dimensionless points are preferred for cover sampling, since increasing point size leads to increasing overestimation of cover (Goodall 1952). Dudley et al. (1998) used the point frame (Levy and Madden 1933) in a horizontal orientation, considering it the most accurate standard for comparison of vegetation density methods where estimates are limited to short distances.

A direct method of horizontal cover measurement based on point estimates should increase objectivity, reduce variability between observers, and produce point data compatible with corresponding point estimates of vertical cover. Such a method should allow estimates over short or long distances and at any height, depending on research objectives and vegetation characteristics. The method should be most efficient when used by 1 person.

\section{Methods}

\section{Development of Technique}

The following technique for estimating horizontal cover was developed. A dimensionless-point target, located at a selected height above ground, was observed from points systematically distributed in a circle of specific radius and height above ground surrounding the target. Each circle of observations was treated as a single observation the same as a set of dependent points from a point frame or point transect is treated as a single observation. Percent of locations around the target from which the target was obscured by vegetation indicated percent cover. Observation heights and sight distances (radii) were selected according to vegetation conditions and sampling interests. The dimensionless point target was represented by the intersection of the upper arc of a $9 \mathrm{~cm}$ ball and the right side of a vertical staff on which the ball was mounted.

In selecting sight distances (radii) from which to observe targets, we reasoned that relatively long distances would more fully integrate the structural variability of a stand (Shimwell 1972) than shorter distances. As with the concept of minimal area, "minimal sight distances" vary greatly depending on kind of plant 
community or stratum being sampled. Empirically determined minimal areas reported by Mueller-Dombois and Ellenberg (1974) converted to the following plot radii (sight distances):

Forests

(including tree stratum)

Forest understory

Dry grassland

Dwarf-shrub heath

Agricultural weed

communities

Hay meadow

$8.0-12.6 \mathrm{~m}$

$4.0-8.0 \mathrm{~m}$

$4.0-5.6 \mathrm{~m}$

$1.8-2.8 \mathrm{~m}$

$2.8-5.6 \mathrm{~m}$

$1.8-2.8 \mathrm{~m}$

We determined that sight distances allowing observation of target points $50 \%$ of the time produced circular plots of approximately the same areas as above. Longer sight distances resulted in cover values approaching or equaling $100 \%$, obscuring differences in cover. Substantially more difficulty and time were required to maintain correct distance and orientation toward targets, when distances resulted in observation of about $70 \%$ or more cover.

In most applications, sight distance was determined only once for a vegetation type. When cover was determined for multiple strata, sight distance was based on the most visible stratum. If any associated strata were more than $90 \%$ obscured at the initial sight distance, a shorter sight distance was selected for those specific strata.

Once a sight distance was selected, the observer walked a complete circle around the target, stopping at systematically selected step locations to determine if the target point could be sighted with 1 eye or through 1 ocular of a pair of binoculars. To avoid biasing location of the observer's eye when reaching each succeeding observation point, a repetitious, stationary posture was assumed prior to looking toward the target. Elevation of the eye was gauged in accordance with marks on an observer-held staff that corresponded to the height(s) of target(s) being observed.

In vegetation less than $3 \mathrm{~m}$ tall, a chord of desired length was attached between the target and observer staffs for maintaining selected sight distances. In taller vegetation, the observer periodically checked distance from target using an optical range finder. The range finder consisted of 2 observer-specific marks on the observer's staff that triangulated from the observer's eye to a $1 \mathrm{~m}$ increment on the target staff, when held at arm's length and at correct distance from the target.

Total locations around the circle from which a target was observed, versus number of locations from which the target was obscured by vegetation, were recorded on hand tally counters and used to compute percent cover. Percent cover was then divided by observation distance to produce a weighted value $(\% / \mathrm{m})$ for comparisons of values obtained at other distances.

\section{Technique Test}

We compared the precision (repeatability) of the staff-ball method against a tubular version (Leckenby 1984) of the profile board (Nudds 1977), a cover pole (Griffith and Youtie 1988), and a checkerboard 40 $\mathrm{cm}$ x $50 \mathrm{~cm}$ having 10 -cm-wide black and white squares. We compared methods in paper birch-white spruce (Betula papyrifera-Picea glauca) forest, because this vegetation necessitated use of a range finder and binoculars, thereby ensuring that all possible time-consuming elements of the staff-ball method would be included in comparisons.

Eight observers estimated percent cover by each of the 4 techniques on the same 10 plots, reading each centrally located target from 22 locations uniformly spaced around a circle of $15 \mathrm{~m}$ radius. The methods were compared only at target and observation heights of $1.25 \mathrm{~m}$, because overlapping movements of 8 observers performing 4 procedures at each plot location resulted in herbaceous ground cover becoming progressively trampled or otherwise disturbed. Observations through 2 oculars and then 1 ocular were recorded separately to document the effect of parallax.

We used a randomized block design (person) to obtain treatment means for each of the 4 cover methods. We modified Levine's test to test for differences in the

Table 1. Mean and modified Levine statistics for 4 cover methods used to measure cover in the 1.5 m strata of a birch-spruce forest.

\begin{tabular}{lcc}
\hline \hline Method & $\begin{array}{c}\text { Mean of } \\
\text { Cover method }\end{array}$ & $\begin{array}{c}\text { Mean of modified Levine } \\
\text { 100 (|cover est - mean // mean })\end{array}$ \\
\hline Staff-ball & 71.83 & 3.52 \\
cover pole & 37.03 & 12.64 \\
profile tube & 63.36 & 7.79 \\
checkerboard & 33.46 & 14.90 \\
\hline
\end{tabular}

Table 2. Contrasts of differences in the precision of the staff-ball cover method versus each of 3 other cover methods used to measure cover in the in $1.5 \mathrm{~m}$ strata of a birch-spruce forest.

\begin{tabular}{lccccc}
\hline \hline Contrast & DF & MS & F Value & t value & Pr>t \\
\hline $\begin{array}{l}\text { staff-ball } \\
\text { vs cover pole }\end{array}$ & 1 & 332.888 & 6.007 & 2.451 & 0.0104 \\
$\begin{array}{l}\text { staff-ball } \\
\text { vs profile tube }\end{array}$ & 1 & 72.705 & 1.312 & 1.145 & 0.1309 \\
$\begin{array}{l}\text { staff-ball } \\
\text { vs checkerboard }\end{array}$ & 1 & 517.781 & 9.343 & 3.057 & 0.0025 \\
\begin{tabular}{l} 
Error \\
\hline
\end{tabular} & 27 & 55.419 & & & \\
\hline
\end{tabular}

between-observer variability of the cover methods. Levine's test is recommended for testing differences in precision (Snedecor and Cochran 1980). Due to the magnitude of difference between treatment means (range: 33.46 to 71.83 ), we wanted a test statistic that weighted the size of the difference relative to the treatment mean. Instead of Levine's method of comparing the absolute differences of the cover measurement from the cover method mean, we compared percent absolute differences:

$$
100\left(\frac{|\mathrm{y}-\overline{\mathrm{y}}|}{\overline{\mathrm{y}}}\right)
$$

A priori, we tested for differences in variability between the staff ball method and each of the other 3 cover methods, using 3 contrast statements. The contrast F-statistics were converted to t-statistics (Bickel and Doksum 1977), to perform a 1-tailed hypothesis test. We were interested in determining if the staff-ball method had significantly less variability than the other 3 methods.

The efficiency of each method was measured by the time required to obtain cover estimates. Observer was treated as a blocking variable in a one-way analysis of variance of total seconds required to observe cover from 10 plots having 22 observations each. Multiple mean comparisons were made using Bonferonni method (Neter and Wasserman 1974), reducing the critical tstatistic to one associated with

$\alpha=(0.01 / 3)=0.0033$.

All statistical tests were performed with $\alpha=0.05$. 


\section{Results and Discussion}

There was a large range in means by cover methods as well as the modified test statistic used in Levine's test (Table 1). The staff-ball method was more precise than either the cover-pole or checkerboard method (Table 2, Fig. 1). While the staffball method was not significantly more precise than the profile-tube at $\alpha=0.05$, it was significant for $\alpha>0.131$.

The staff-ball method was significantly faster $(\mathrm{p}<0.05)$ than any of the other methods (Table 3), presumably, because it required only simple yes:no decisions rather than subjective estimates and/or counts, and it did not require repeated repositioning of the target.

In a separate test at an observation distance of $4 \mathrm{~m}$, where binoculars were not necessary to observe the target, the method averaged 5.1 times faster than the density board, 5.8 times faster than the cover pole, and 14.3 times faster than the checkerboard.

Across all observers, the $1.5-\mathrm{m}$ stratum of birch-spruce forest vegetation averaged $21 \%$ less cover when both eyes were used. Similar differences were observed with the other cover methods when 1 versus both eyes was used. This reinforced the importance of sighting with 1 eye to avoid parallax problems and to obtain true point values.

In use of any horizontal cover technique, we believe it is important for sampling protocol to address the significance of observation height relative to target height, by requiring consistency between observers and across specific data collec-

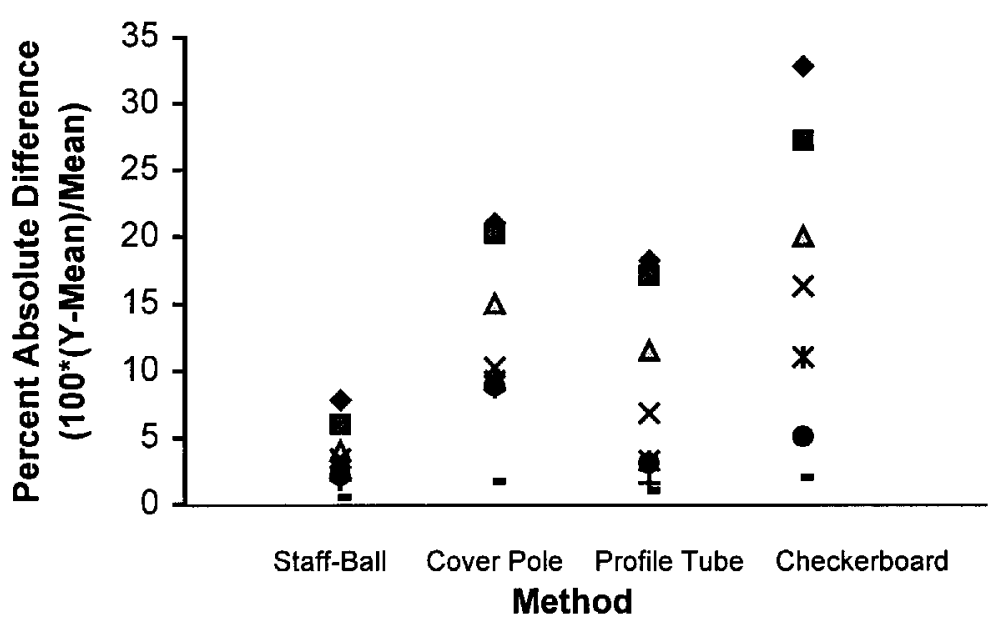

Fig. 1. Plot of modified Levine statistic by method and person. Individual observers are represented by different symbols.

tions or comparisons. Variability as a result of inconsistent observation heights is particularly significant in vegetation types where substantial differences in foliage/stem density occur with plant height (Fig 2). For example, in some birch-spruce forests an understory shrub, high bushcranberry (Viburnum edule (Michx.) Raf.), has a sharply defined upper boundary at about $125 \mathrm{~cm}$ height, below which there is an 11-fold increase in horizontal cover. Observations of cover targets positioned $25 \mathrm{~cm}$ below the upper boundary of that shrub stratum and $15 \mathrm{~m}$ from the observer varied by about $20 \%$ when observers, 172 and $187 \mathrm{~cm}$ tall, viewed the target from an erect stance.
If a study does not require cover measurements by stratum or strictly parallel to ground surface, targets may be observed from other heights, as long as angles of observation are consistent between observers and/or comparative uses of data. Such deviation from sampling within a stratum will enable sampling at heights exceeding that of the observer (e. g. nest sites in a tree or tall shrub canopy). In any case, consistency in heights of targets and heights of observation are necessary.

Mean horizontal cover is directly proportional to distance over which point observations are made. Therefore, sight distances may be varied from one stratum to another, if differences in vegetation

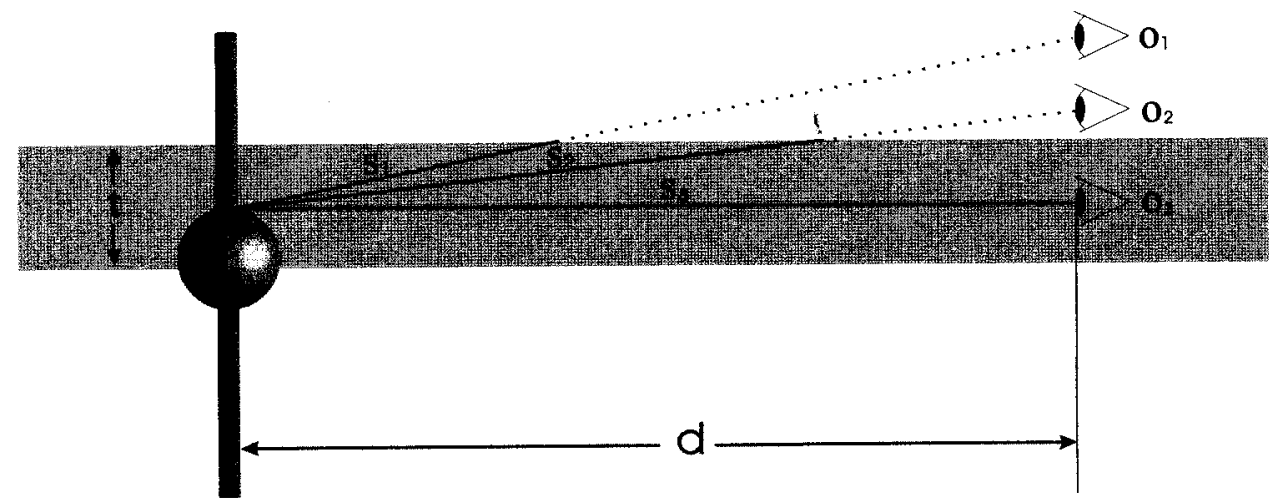

Fig. 2. Errors in cover measurements caused by differences in angles of observation. Only a truly horizontal sight $\left(S_{3}\right)$ from $\mathrm{O}_{3}$ accurately intersects all cover within a vegetation stratum (shaded area). Observations from $\mathrm{O}_{1}$ and $\mathrm{O}_{2}$ not only fail to measure all cover within the stratum, but differences between actual amounts of cover intersected by sight lines $S_{1}$ and $S_{2}$ contribute to significant variation between observers. 
Table 3. Contrasts between staff-ball and 3 other techniques relative to time necessary to observe cover from 220 locations in the $1.5 \mathrm{~m}$ strata of a birch-spruce forest.

\begin{tabular}{lcccccc}
\hline \hline Contrast & DF & Difference & MS & F Value & t value & $\operatorname{Pr}<\mathrm{t}$ \\
\hline $\begin{array}{l}\text { Staff-ball } \\
\quad \text { vs cover pole }\end{array}$ & 1 & -933 & $1,972,098$ & 242.46 & -15.571 & 0.0000 \\
$\begin{array}{l}\text { Staff-ball } \\
\quad \text { vs profile board }\end{array}$ & 1 & -758 & $1,149,128$ & 141.28 & $-11,886$ & 0.0000 \\
$\begin{array}{l}\text { Staff-ball } \\
\quad \text { vs checkerboard }\end{array}$ & 1 & $-12,005$ & $288,240,050$ & $35,438.40$ & -188.251 & 0.0000 \\
Error & 9 & & $8,133.56$ & & & \\
\hline
\end{tabular}

cover limit efficiency or accuracy of observation across all strata from the same sight distance. This flexibility also allows cover estimation on different scales, such as for comparison of a specific nest or bed site (e.g. distinct plant or clump of vegetation) and the overall stand.

The staff-ball method allowed more objective, more precise, and faster estimates of horizontal cover than profile boards (tubes), cover poles or checkerboards. As a method to index horizontal cover, the staff-ball will produce the most repeatable and consistent results among observers and over time. Assuming that point values are the most accurate indicators of cover, staff-ball estimates should also more closely reflect true values. The staff-ball method was versatile in application and most efficiently used by 1 person.

Bickel, P.J. and K.A. Doksum. 1977. Mathematical statistics: linear basic ideas and selected topics. Holden-Day Inc. San Francisco, Calif

Bonham, C.D. 1989. Measurements for terrestrial vegetation. John Wiley and Sons. New York, N. Y.

Dudley, S.J., C.D. Bonham, S.R. Abt, and J.C. Fischenich. 1998. Comparison of methods for measuring woody riparian vegetation density. J. Arid Environ. 38:77-86.

Goodall, D.W. 1952. Some considerations in the use of point quadrats for the analysis of vegetation. Aust. J. Sci. Res. Ser. B. 5:1-41.

Greig-Smith, P. 1964. Quantitative plant ecology, Second ed. Butterworths. London.

Griffith, B. and B.A. Youtie. 1988. Two devices for estimating foliage density and deer hiding cover. Wildl. Soc. Bull.
Higgins, K.F., J.L. Oldemeyer, K.J. Jenkins, G.K. Clambey, and R.F. Harlow. 1994. Vegetation sampling and measurement. p. 567-591. In: T. A. Bookhout, ed. Research and management techniques for wildlife and habitats. Fifth ed. The Wildl. Soc., Bethesda, Md.

Leckenby, D.A. 1984. Elk use and availability of cover and forage habitat components in the Blue Mountains, northeast Oregon 1976-1982. Oregon Dept. of Fish and Wildl., Wildl. Res. Rep. No. 14.

Levy, E.B. and E.A. Madden. 1933. The point method of pasture analysis. N. Z. J. Agr. 46:267-279.

Lyon, L.J. and C.L. Marcum. 1986. Field test of a PC program to evaluate hiding cover for elk. p. 271-274. In: Western States and Provinces Elk Workshop Proc. Oregon Dept. Fish and Wildlife. 16:206-210.
Mueller-Dombois, D. and H. Ellenberg. 1974. Aims and methods of vegetation ecology. John Wiley and Sons, New York, New York.

Neter, J. and W. Wasserman. 1974. Applied linear statistical models. Richard D. Irwin, Inc., Homewood, Ill.

Nudds, T.D. 1977. Quantifying the vegetative structure of wildlife cover. Wildl. Soc. Bull. 5:113-117.

Shimwell, D.W. 1972. The description and classification of vegetation. Univ. of Washington Press. Seattle, Washington.

Snedecor, G.W. and W.G. Cochran. 1980. Statistical methods. Iowa State University Press. Ames, Iowa 